Artigo

\title{
A MULHER NA CIDADE - UMA PROPOSTA METODOLÓGICA PARA A ANÁLISE DO ESPAÇO URBANO SOB A PERSPECTIVA DO MOVIMENTO DE MULHERES NA CIDADE DE SALVADOR
}

\author{
WOMEN IN THE CITY - A METHODOLOGICAL PROPOSAL FOR THE ANALYSIS \\ OF URBAN SPACE FROM THE PERSPECTIVE OF WOMEN'S MOVEMENT IN THE \\ CITY OF SALVADOR
}

\author{
MUJERES EN LA CIUDAD: UNA PROPUESTA METODOLÓGICA PARA EL \\ ANÁLISIS DEL ESPACIO URBANO DESDE LA PERSPECTIVA DEL MOVIMIENTO \\ DE LAS MUJERES EN LA CIUDAD DE SALVADOR
}

\author{
Júlia Garcia de Souza da Silva
}

\begin{abstract}
Resumo
Este artigo tem por objetivo construir um caminho metodológico para a análise do Espaço Urbano a partir da articulação da ciência geográfica e da epistemologia feminista socialista, buscando o nó que imbrica as relações sociais de sexo, raça/etnia e classe com o espaço geográfico. Visa-se aqui enfatizar a abordagem sobre a dimensão espacial nas relações sociais de sexo, bem como as relações sociais de sexo, raça/etnia e classe com a produção do espaço urbano. As metodologias feministas, no plural, são o resultado de um processo histórico de contestação à ciência positivista e utilizada para construir um conhecimento que tenha por finalidade a transformação social. Para a realização desse texto, foi feita uma revisão bibliográfica enfocando as metodologias de análise do Feminismo Materialista e da metodologia perspectivista, a fim de iniciar a compreensão de como a pesquisa feminista contribui para analisar as formas que as relações sociais de sexo se expressam na produção e reprodução do espaço urbano. A centralidade dessa análise é a compreensão do olhar do movimento feminista para as cidades, com ênfase à cidade de Salvador. Parte-se aqui, da análise do espaço geográfico como um espaço de reprodução das relações do sistema capitalistapatriarcal-racista e suas contradições. Busca-se compreender como se dá a perpetuação das relações sociais de sexo a partir do uso e ocupação do solo e como a metodologia feminista serve à ciência geográfica, e vice-versa, para que a produção e a reprodução do espaço seja compreendida à sua totalidade.
\end{abstract}

\begin{abstract}
This article aims to build a methodological way to analyze the urban space from the articulation between geographic science and socialist feminist epistemology. It is seeks connection node that imbues social relations, sex, race/ethnicity and class with the geographical space. It is aimed here to emphasize the approach on the spatial dimension in the social relations of sex as well as social relations, sex, race/ethnicity and class with the production of urban space. The feminist methodologies, in the plural, are the result of a historic process of contesting positivist science and they were used to build knowledge that aims at social transformation. In this text, it made a bibliographic review. The focus was the methodologies to analysis of Materialist Feminism and the perspective methodology, with the intention of start understanding how feminist research contributes to analyzing the ways that social relations of sex are expressed in the production and reproduction of urban space. The centrality of this analysis is the comprehension of the feminist movement's view of cities, with an emphasis on the city of Salvador. It starts here, from the analysis of the geographical space as a reproduction space of the
\end{abstract}


relations of the capitalist-patriarchal-racist system and its contradictions. It seeks to understand how it is possible to happen the perpetuation of social relations of sex occurs from the use and occupation of the soil and how feminist methodology serves geographic science, and vice versa, for the production and reproduction of space is fully understood.

\section{Resumen}

Este artículo tiene como objetivo construir un camino metodológico para el análisis del espacio urbano a partir de la articulación de la ciencia geográfica y la epistemología socialista feminista, buscando el nudo que entrelaza las relaciones sociales de sexo, raza / etnia y clase con el espacio geográfico. El objetivo aquí es enfatizar el enfoque sobre la dimensión espacial en las relaciones sociales de sexo, así como las relaciones sociales de sexo, raza / etnia y clase con la producción del espacio urbano. Las metodologías feministas, en plural, son el resultado de un proceso histórico de impugnación de la ciencia positivista y se utilizan para construir conocimiento que apunta a la transformación social. Para la realización de este texto, se realizó una revisión bibliográfica centrada en las metodologías de análisis del feminismo materialista y la metodología de la perspectiva, para comenzar a comprender cómo la investigación feminista contribuye a analizar las formas en que las relaciones sociales del sexo se expresan en la producción. y reproducción del espacio urbano. La centralidad de este análisis es la comprensión de la visión del movimiento feminista de las ciudades, con énfasis en la ciudad de Salvador. Comienza aquí, a partir del análisis del espacio geográfico como espacio de reproducción de las relaciones del sistema capitalistapatriarcal-racista y sus contradicciones. Busca entender cómo se produce la perpetuación de las relaciones sociales del sexo a partir del uso y la ocupación del suelo y cómo la metodología feminista sirve a la ciencia geográfica, y viceversa, para que la producción y reproducción del espacio se entiendan por sí mismas totalidad.

Palavras-chave: Direitos; Feminismo; Geografia Feminista; Movimentos Feministas. Keywords: Rights; Feminism; Feminist Geography; Feminist Movements.

Palabras clave: Derechos; Feminismo; Geografía feminista; Movimientos feministas.

\section{INTRODUÇÃO}

O espaço enquanto objeto de estudo da Geografia passou, e continua passando, por diversas transformações ao longo do tempo, processo que tem permitido a evolução de seu conceito e sua multiplicidade, conforme as dinâmicas do debate teórico conceitual. Os conceitos e categorias não foram tratados neste trabalho de forma imutável, pois compreende-se que as definições devem ser tratadas de forma flexível, visto que representam 0 momento histórico ao qual os definem. Nessa perspectiva, a geografia marxista se empenhou na tarefa de incorporar o materialismo histórico e dialético como método para a realização da análise das contradições sociais no espaço. Colocase a categoria trabalho enquanto objeto central, uma vez que a produção e reprodução do espaço parte da relação homem-natureza.

A configuração da geografia como mundo circundante decorre do fato de que a existência humana é garantida pelo trabalho dos homens. Pelo seu trabalho os homens transformam a natureza em objetos para consumo e para lhes aumentar a sua capacidade de trabalho. A natureza fornece o material, que o trabalho do homem transformará nos objetos com os quais satisfará a suas necessidades variadas. (MOREIRA, 1985, p. 68). 
Entende-se que o trabalho constituiu o homem e a mulher, ser social, tal qual é hoje. Isto é, a interação da humanidade com o mundo natural, de tal modo que os elementos deste último são conscientemente modificados para alcançar um determinado propósito. O trabalho é a forma pela qual o homem e a mulher se apropriam da natureza a fim de modificá-la de acordo com suas necessidades. As relações dos seres humanos entre si e com a natureza são mediadas pelo trabalho e o desenvolvimento dessas relações na história criam as relações socioeconômicas e socioespaciais. "É no trabalho social que os homens estabelecem relações entre si e, a partir destas, com a natureza". (CORRÊA, 1986, p. 54).

Portanto, o trabalho apresenta uma centralidade fundante do ser social e no conjunto de atividades intelectuais e manuais organizadas pela espécie humana e aplicada sobre a natureza, visando assegurar sua existência. Segundo Marx (1844), os homens - e mulheres -, para existirem, devem ser capazes de se reproduzirem enquanto seres humanos e a forma específica desta reprodução é dada por uma peculiar relação dos seres humanos com a natureza através do trabalho. A categoria do trabalho emerge, desta forma, como categoria central do ser social.

Baseando-se nas concepções da dialética marxista, reforça-se aqui que sem o trabalho o ser humano não poderia existir socialmente, pois ao mesmo tempo em que ele transforma a natureza, diante do trabalho, vai transformando, também, o seu próprio ser. Neste processo transforma o trabalho social em um fator fundamental para a sociabilidade humana, como vemos em:

Como criador de valores de uso, como trabalho útil, é o trabalho, por isso, uma condição de existência do homem, independente de todas as formas de sociedade, eterna necessidade natural de mediação do metabolismo entre homem e natureza e, portanto, vida humana. (MARX, 2008, p.218)

O materialismo histórico dialético foi amplamente utilizado no processo de renovação da geografia que ocorreu entre os anos 1960-1980, a partir de elaborações sobre a relação tempo-espaço enquanto materialidade fundamental da dialética socioespacial. O "espaço", aqui tomado como categoria, será interpretado a partir dos processos em curso, dando ênfase ao espaço urbano, a fim de se entender a mulher na cidade, com o absoluto esforço de superar as relações reducionistas da lógica formal, associando a dialética à noção de movimento.

O espaço, então, é aqui considerado como uma construção social histórica, ou seja, como meio, condição e produto das relações sociais de produção, relações estas inseridas no sistema econômico hegemônico, condicionando-as ao modo de produção capitalista, reproduzindo suas desigualdades e contradições. Em meio a esse debate Camacho (2010) aponta que:

O espaço geográfico é uma totalidade dinâmica e contraditória produzida historicamente na relação entre sociedade e natureza mediada pelas relações de trabalho, ou seja, o que temos no processo de produção espacial é a natureza primitiva transformada em segunda natureza, este é o processo de 
historicização/humanização/socialização da natureza. Todavia, partindo do pressuposto que as relações de trabalho se encontram subordinadas ao modo de produção capitalista, o processo de produção do espaço se faz condicionado, também, ao capitalismo que tem como características inerentes a sua lógica a produção/ reprodução e acumulação do capital fruto da exploração do trabalho, gerando como consequências: as desigualdades, as contradições e a luta de classes. (CAMACHO, 2010. p. 75)

As cidades, por sua vez, ao serem produtos históricos da construção humana refletem a estrutura da sociedade e, nesse sentido, é perceptível, também no ambiente urbano, o impacto dessas contradições na vivência cotidiana das mulheres. Sob este aspecto, deve-se enfatizar que a produção do espaço se dá a partir da ação de fatores determinantes e não de forma espontânea ou aleatória, e, no sistema capitalista-patriarcal-racista o poder econômico e o Estado Burguês atuam como preponderantes no processo de produção, como afirma Corrêa:

Organização espacial é o resultado do trabalho humano acumulado ao longo do tempo. No capitalismo, este trabalho realiza-se sob o comando do capital, quer dizer, dos diferentes proprietários dos diversos tipos de capital. Também é realizado através da ação do Estado capitalista. Isto quer dizer que o capital e seu Estado são os agentes da organização do espaço. Daí falar-se em espaço do capital. (CORRÊA, 1986, p. 61).

Ainda nesse sentido Rossini (2009) afirma que:

Se o processo de produção do espaço é um processo de trabalho, as parcelas do espaço global se articulam e se integram a partir do papel que cada uma terá no processo de trabalho geral. Estabelece-se então uma diversidade de relações com intensidades desiguais, que vão produzir o espaço global mediante a produção de parcelas espaciais menores. $\mathrm{Na}$ formação econômica da sociedade capitalista, a categoria determinante da análise é o capital. Desse modo teremos uma produção espacial voltada para as exigências e necessidades do capital, uma população que se produzirá e reproduzirá em função de suas leis e, consequentemente, um processo de apropriação que lhe será peculiar. (ROSSINI, 2009. p. 10)

Partindo-se desse pressuposto e alicerçando-se nos argumentos de Rossini (2009), é que se busca construir a análise da relação entre as relações sociais de sexo e a (re)produção do espaço urbano. Para uma análise do modelo de desenvolvimento urbano a partir de uma perspectiva feminista, em um primeiro momento é necessário reconhecer que as mulheres ocupam posição de desigualdade neste modelo. Sendo assim, as mesmas sofrem de forma diferenciada os impactos do mesmo sobre suas vidas, corpos e territórios.

Os impactos da urbanização corporativa, apesar de amplamente sentidos por toda a classe trabalhadora, têm um efeito ainda mais perverso na vida das mulheres e existem impactos vivenciados apenas por elas. Entre as violações 
que afetam diretamente a vida das mulheres, denunciamos as violências sofridas no transporte público, as condições de vulnerabilidade na moradia e no trabalho, o aumento da sobrecarga do trabalho pelo escasseamento dos equipamentos públicos como creches e cozinhas comunitárias, além da redução na participação política e nas decisões legais de negociação com as prefeituras no processo de formulação dos Planos Diretores de Desenvolvimento Urbano.

Além da expulsão por meio da gentrificação dos centros urbanos, a urbanização corporativa, altamente lastreada nos interesses do capital, destrói também bens imateriais da população local, como a cultura. Trata-se de uma forma de expropriação e violência que atinge, sobretudo, a classe trabalhadora moradora da periferia das grandes cidades, que em sua grande maioria são as mulheres negras. Estas também são impactadas pela quebra de vizinhança nessas áreas, ocasionando uma ruptura das relações de solidariedade, que é uma das principais formas das mulheres terem condição de sobrevivência na cidade.

As desigualdades de poder na definição sobre o uso dado ao espaço geográfico, às formas distintas de sua apropriação, tendem a ser invisibilizadas no momento de implementação de um projeto de cidade e a forma como são avaliados os critérios que orientam a escolha sobre a implementação são atravessadas pelas determinantes de classe, sexo e raça/etnia que definem as relações desiguais de poder na sociedade.

As áreas urbanas são marcadas pelas desigualdades de acesso e de direitos. A população se torna refém da especulação imobiliária, principalmente as mulheres, que, sem alternativas de autonomia econômica, ocupam postos de trabalho altamente precarizados, buscando flexibilidade de horários que se expressa também na flexibilização dos direitos, usando grande parte do seu tempo diário para os deslocamentos entre, casa, trabalho, escola de crianças, postos de saúde, mercados e feiras, enquanto que os homens têm seus deslocamentos reduzidos à casa, trabalho, estudos e lazer.

A ideia de que o ambiente construído reflete os estereótipos dos lugares femininos e masculinos e que houve uma ótica masculina na produção do espaço urbano foi defendida por Bondi (1992). Ela argumenta que o planejamento urbano funcionalista e racionalista que domina o modo de concepção de cidade aprisiona as mulheres em determinados lugares ao separar as áreas comerciais, industriais e residenciais, acentuando a divisão do trabalho entre os sexos.

A expressão de que o espaço geográfico é a materialização da sociedade e de que toda a existência humana é espacial é uma concepção plenamente aceita pelos cientistas da geografia. Contudo, nem toda a humanidade esteve expressa no conhecimento geográfico. Esta crítica fundamenta o célebre artigo das geógrafas norteamericanas Janice Monk e Susan Hanson, intitulado 'On not excluding half of the human in human geography', presente na revista 'The professional geographer' da Association of American Geographers de 1982. Este artigo denuncia as relações de poder inerentes à produção do espaço geográfico, a hegemonia androcêntrica que the é inerente e a invisibilidade feminina. Deste movimento emergem iniciativas de tornar visíveis grupos ausentes da produção científica geográfica e desenvolvem-se os estudos sobre as mulheres, 
gays e lésbicas, procurando evidenciar suas expressões materiais de produção do espaço, como a distribuição espacial das moradias e áreas de lazer, os deslocamentos físicos e as inserções de tais grupos nas relações produtivas e reprodutivas da sociedade burguesa e patriarcal. (SILVA, 2010. p. 41)

A concepção de cidade, segundo os trabalhos feministas, reforçava os papéis tradicionais de homens e mulheres e constituía uma barreira para a superação das desigualdades entre os grupos sociais masculino e feminino, uma vez que separava, de forma contundente, as esferas públicas e privadas, como pode ser visto em McDowell (1983, p. 116).

Outras críticas às abordagens das relações sociais de sexo e espaço que mobilizou o campo das Geografias Feministas ocorreu nos anos 90, e esteve centrado na discussão em torno da primazia da compreensão bipolarizada e oposicional entre o feminino e o masculino. Além disso, as críticas eram direcionadas também à adoção de uma feminilidade genérica, pautada pelas relações de classes e fundamentada na figura da mulher esposa, mãe, heterossexual, branca e trabalhadora, que relegava a planos inferiores outras identidades marcadas por sistemas políticos e culturais de opressão, como a sexualidade e a racialidade. Sendo assim, afirma que a leitura da distribuição funcional da paisagem urbana reflete a dominância da perspectiva masculina sobre o espaço.

Sob esta concepção, foram criticados os padrões de uso e ocupação da terra que separam as áreas residenciais dos espaços produtivos e de serviços, além da qualidade dos sistemas de transporte, que dificultavam a mobilidade urbana das mulheres, responsáveis pela vida familiar, e sua ascensão às oportunidades de trabalho e de estudo.

Huxley e Winchester (1991, p. 16) argumentam que os processos de segregação espacial, além da compreensão da lógica capitalista que os define, relaciona-se com o modelo social patriarcal, visto que muitas áreas são compostas pelo trabalho feminino remunerado de forma desigual em relação ao trabalho masculino, gerando uma feminização da pobreza urbana. A combinação de capitalismo, patriarcado e racismo alija as mulheres da apropriação da cidade.

Enfim, os espaços de constrangimento, como a rua em determinados locais e horários, ou espaços de confinamento, como as residências em periferias distantes, são claramente elementos que tanto se referem às diferenças de acesso físico entre mulheres e homens a determinados espaços, como a construção de barreiras invisíveis criadas pelo olhar e força daqueles que impõem sua ordem e alcançam legitimidade.

A superação das desigualdades socioespaciais passa necessariamente pela compreensão dos fenômenos estruturantes em sua formação e a formulação de políticas específicas para além das disputas econômicas em torno de sua produção, tendo em vista que o espaço é resultado da ação humana em todas as suas dimensões, cujo direito é fundamental para o avanço no processo de cidadania dos grupos excluídos. Tendo por base o materialismo-históricodialético como método de análise da realidade, temos condições de expor as contradições na produção do espaço urbano e o uso e ocupação do solo urbano como forma de manter as relações de poder entre os sexos, a fim de superar essa condição de existência oprimida, explorada e dominada das mulheres nas cidades, a caminho do "Direito à Cidade". 
O direito à cidade é aqui compreendido como a apropriação de todos os grupos sociais à cidade, o que desafia a lógica do mercado e reafirma a cidade como proveito para quem nela vive, exprimindo-lhe um novo significado construído coletivamente, a partir dos desígnios humanos e não do Capital, isso só se torna possível se o urbanismo for feminista, combatendo o sistema de opressão-exploração e construindo meios de atender as diferentes demandas nas formas de ocupação da cidade.

\section{A GEOGRAFIA FEMINISTA: ONDE AS EPISTEMOLOGIAS SE ENCONTRAM?}

A Geografia Feminista nasce no contexto da segunda onda do movimento feminista e apresenta-se a partir de duas vertentes de análise a primeira referese à produção científica das mulheres na geografia, ciência altamente masculinizada, e a segunda se refere à interpretação das categorias geográficas, já consolidadas, a partir da perspectiva do feminismo, ou seja, a busca da compreensão do "Espaço", "Território", "Lugar", e outros, a partir da inserção das relações sociais de sexo como fator relevante, ou, de forma mais enfática, estruturante.

A geografia feminista busca articular as categorias que atuam na produção e reprodução das relações produzidas no Espaço, entendendo que dessa forma é possível revelar a forma hierárquica e desigual que se dão essas relações, tanto na casa, como no trabalho e na comunidade, e, ampliando a escala, entender como essas relações se dão nas cidades. Para MARTíNEZ (1995), existem três grandes áreas na Geografia onde são fundamentais a perspectiva das relações sociais de sexo:

as relações existentes entre gênero e conceitos chaves na Geografia como são o espaço, o lugar e a natureza; o espaço enquanto construção social e de gênero, o conceito de lugar e a importância que em sua definição introduzem as diferenças de gênero, a relação entre gênero e natureza (o meio ambiente em seu sentido amplo); 2) as diferenças territoriais nos papéis e relações de gênero; 3) o uso e experiência diferenciais do espaço entre homens e mulheres, em distintas escalas: desde a escala local (utilização do espaço cotidiano, por exemplo) a global (movimentos migratórios transnacionais) (MARTINEZ, 1995, p. 18).

Essa visão apresenta uma forma de resistência tanto na geografia, bem como em toda a ciência, a qual a epistemologia feminista questiona e propõe novas abordagens teóricas e metodológicas. Sandra Harding (1993) afirma que a ciência tem sido deturpada pela visão hegemônica, branca e masculina, que parcializa e negligencia a totalidade, não apenas no que se refere às teorias, seus conceitos e métodos de investigação, mas, sobretudo na formulação das questões, prioridades e na interpretação dos resultados, já que os dados podem corresponder a qualquer interesse e responder a quaisquer questões colocadas pelo pesquisador.

Entende-se aqui que o feminismo e sua produção científica está comprometido com um projeto político de transformação social, que busca o fim das relações desiguais e hierárquicas produzidas para perpetuar sistemas hegemônicos de dominação-exploração e manutenção do poder. Nesse sentido, 
a Geografia feminista busca uma transformação não só da Geografia, mas também da sociedade como um todo.

Entendido que o espaço não é neutro do ponto de vista das relações sociais de sexo, classe e raça, torna-se fundamental, para uma análise real desse espaço, a incorporação do conteúdo feminista que evidencia as diferentes formas de apropriação do espaço entre o grupo social feminino e masculino, além da divisão racial, também estruturante no sistema capitalista-patriarcalracista. Ângela Davis (2016) enfatiza que as diversas opressões que decorrem dessas categorias não devem se hierarquizar, mas estar lado a lado na luta pela transformação de nossas cidades e da sociedade.

É nesse sentido que se busca aqui construir uma metodologia que tenha a análise fundamentada no ponto de vista das feministas, a partir da concepção de que a ciência expressa a cientista e sua visão de mundo, a partir das suas vivências, experiências e objetivos. Tomando por base autoras como Sandra Harding, Dorothy Smith, Donna Haraway, entre outras, para as quais, os procedimentos conceituais e metodológicos são construídos a partir de determinada posição na sociedade, também conhecido como Standpoint Theory.

Entende-se aqui que "ponto de vista" é um lugar a partir do qual uma pessoa vê o mundo, porém, isso não significa afirmar que só é possível escrever sobre determinado assunto no caso de ser sujeita do fenômeno analisado, mas, evidenciar no procedimento científico que a objetividade e neutralidade são falácias construídas pelo positivismo e que não é possível produzir conhecimento que não expresse a base material ou a realidade concreta da autora. A formação do conhecimento não é neutra, não é somente objetiva, vem sempre contagiada por nossas experiências pessoais e ideológicas, dado que reforça a importância de termos mais mulheres pensando a cidade.

Visto isso, a geografia feminista, aqui compreendida como epistemologia a ser adotada, busca fazer análises sobre a cidade, que revelem que o espaço urbano não é neutro, sobretudo se avaliado na perspectiva das relações sociais de sexo, classe e raça. Todo o processo de produção e reprodução do espaço é definido pelos diversos atores que o realizam, tanto no âmbito da produção capitalista, que apresenta suas frações (industrial, imobiliário, especulativo...), bem como o Estado, que realiza o ordenamento de acordo com os interesses da classe hegemônica, e a resistência, construída por quem vive a cidade e nela reproduz as suas condições de vida e trabalho, pois, apesar da cidade crescer segregada e privatizada, não se pode escamotear que onde há repressão, há insurgência.

Busca-se aqui um caminho metodológico que tem a intenção de desvelar as diferentes formas que os grupos sociais masculino e feminino se relacionam com a cidade, que são diferenças e hierarquias que reproduzem e perpetuam os locais e papeis historicamente desempenhados nas relações sociais de classe, sexo e raça, condicionados pelo modo de produção capitalista do espaço urbano, que dita a localização dos serviços, a quantidade e qualidade destes, na cidade. Conforme Rainero,

El análisis de género está estrechamente vinculado con el análisis de la urbanización en tanto ésta es expresión de las relaciones de género y al mismo tiempo que la organización físico espacial de la ciudad, contribuye a reproducir o promover cambios en los roles y relaciones entre hombres y mujeres. (RAINEIRO, 1988) 
Apresenta-se aqui a Geografia Feminista e Perspectivista como uma síntese metodológica que evidencie o encontro de duas ciências, que, a meu ver, nunca foi possível separá-las, entendendo que todas as relações se dão em um Espaço geográfico e que toda a produção desse espaço expressa as relações sociais. Então, a imbricação, novelo, nó, entre as categorias sexo, raça, classe e espaço geográfico se tornam fundamentais para uma análise cada vez mais próxima da realidade e da coerência científica aqui almejada.

\section{MULHER, CASA E CIDADE: O PÚBLICO, O PRIVADO E A FAMÍlIA NUCLEAR NA CONTRADIÇÃO "LAR" $X$ "RUA"}

A afirmação "O pessoal é Político", atribuída a Kate Millet, foi um dos grandes marcos da segunda onda do feminismo e ajuda a romper com a dicotomia e polarização entre a produção e a reprodução. A compreensão da onipresença do político foi um dos grandes resultados contemporâneos do avanço da teoria e da luta feminista, pois a partir dela podem ser problematizadas outras dicotomias: emoção $x$ razão, lar $x$ rua, trabalho remunerado $x$ trabalho gratuito, mulher reprodutora $x$ homem produtor, mulher passiva $\mathrm{x}$ homem ativo.

Entendemos aqui, a partir dessa perspectiva, que o público e o privado são estreitamente imbricados. Essa dissociação entre espaço da produção e da reprodução, tão claramente visível nas práticas sociais e que subordina esta à aquela, acaba por alocar prioritária e majoritariamente a mulher na esfera da reprodução, constituindo-se, portanto, em uma das formas mais contundentes do aparecer da desigualdade de gênero e sob a qual se sustenta a supremacia masculina na divisão sexual do trabalho.

Para efeito dessa reflexão resgatamos Saffioti (1988. p. 144), quando ela afirma que as relações sociais de produção não se restringem ao domínio "público" invadindo a área "privada" das relações sociais de reprodução, da mesma forma como as relações sociais de reprodução extrapolam a esfera "privada", penetrando vigorosamente no âmbito da produção "pública", ademais, a terra, a casa e as benfeitorias se prestam ao seu possuidor para uma utilização; uso para habitar. uso ligado diretamente aos interesses da reprodução da força de trabalho, na medida em que o conforto, a proteção e a segurança que a moradia pode proporcionar é componente fundamental para a sustentação do modelo econômico. porque fornece algumas condições essenciais para que o(a) trabalhador(a) possa diariamente retomar a sua atividade produtiva cotidiana.

Enquanto que, para os homens, o domínio do espaço público, a ocupação da "rua", o acesso e o direito às cidades, sempre foi algo naturalizado. Para as mulheres, o confinamento no lar, entre as classes altas, e a violência urbana, entre as mulheres em condições de vulnerabilidade, são as regras, entendendo isso como uma determinante no processo de produção e reprodução das cidades e casas. A família nuclear ocidental é uma "célula" de produção da vida e, evidentemente, em uma sociedade capitalista-patriarcal-racista, de produção de mercadoria, no caso, a "força de trabalho". Como elucida Saffioti:

O trabalho doméstico, por exemplo, caracteriza-se pela produção de valores de uso diretamente consumidos pela família, não podendo afirmar que esteja organizado em moldes capitalistas, embora a dona de casa que o executa possa estar fortemente imbuída das ideologias dominantes na sociedade 
capitalista de consumo de massa. Embora o fruto de seu trabalho não venda no mercado capitalista, a dona de casa desempenha função importantíssima na preservação do sistema capitalista, na medida em que os serviços que presta incidem diretamente na produção e na reprodução da força de trabalho, mercadoria imprescindível à reprodução do capital. Não se poderia, entretanto, falar em modo de produção doméstico, já que a organização do trabalho não recobre todas as instâncias necessárias à constituição de um modo de produção, mas imbrica-se no modo de produção capitalista ao qual serve. (SAFIOTTI, 1976, p. 5)

Essa responsabilização pela produção e reprodução da vida, expresso no trabalho doméstico e de cuidados, faz com que a relação da mulher com a cidade seja fundamentalmente diversa da forma que os homens experienciam esse espaço,

\begin{abstract}
Historicamente, as mulheres viveram as cidades em outros planos e dimensões, que não os da objetividade construtiva da arquitetura e do urbanismo. Além disso, o modo como a mulher existe e se move na cidade é obviamente diverso do modo masculino de ser e se conduzir no espaço urbano. $E$ não digo isso em termos vagos, ainda que verdadeiros, no sentido de que são distintos os modos masculinos e femininos de lidar com o mundo. (RISÉRIO, 2015, p. 265)
\end{abstract}

Podemos afirmar então, que, o formato familiar que o Estado fomenta, atendendo aos interesses do mercado, é o que retira do próprio o peso das responsabilidades com o "bem-estar" e a sobrevivência dos trabalhadores e trabalhadoras, tendo em vista, que, quanto mais essa responsabilidade é negligenciada pelo Estado, maior é o peso que as mulheres carregam, sendo as únicas legitimamente guardiãs dessas tarefas.

Contudo, é importante ressaltar que esse modelo, mesmo resguardando os seus princípios de condicionar a produção capitalista do Espaço, se modifica de acordo com as necessidades do sistema, é o movimento real da história que define qual o tipo de família é necessária para um melhor desenvolvimento dos processos produtivos, como nos elucida Castro, 2009:

Con respecto a los modos en que el Estado modifica las relaciones familiares y las concepciones de familia "deseable" en relación a coyunturas históricas, económicas, y políticas; GRASSI señala que actualmente el estado argentino sostiene un discurso instrumental en relación a las esferas público/privado, diferentes al que se planteaba hasta los años setenta. A medida que el estado renuncia sus antiguas funciones en relación al bienestar social, como producto de los cambios en el modelo de acumulación capitalista y las políticas neoliberales, relega a las familias y comunidades su papel en cuanto a la reproducción material e ideológica, reivindicándolos como ámbitos de "autonomía" y promoviéndola como el ambito privado por antonomasia. (CASTRO, 2009, P. 3) 
Ainda sobre a contextualização histórica do sentido de "família", Castro reforça:

Un recorrido histórico por los últimos doscientos años de Occidente, nos permiten entender que el modelo de familia nuclear y los roles asociados a ella, no son naturales, sino que están fuertemente asociados a los cambios que introdujo el proceso de industrialización. En la sociedad occidental preindustrial, la familia constituía una unidad de producción, reproducción social y consumo. Con el desarrollo de la sociedad industrial estos ámbitos comienzan a disociarse y a producirse una diferenciación entre el ámbito doméstico y el ámbito público o político. Es entonces cuando la familia comienza a ser visualizada, en el mundo occidental, como el refugio a la privacidad, el ambito donde se recrean las relaciones solidarias y de afecto contrarias al dominio del Estado y los valores del mercado; reservándole a la mujer un papel central en este ámbito. (CASTRO, 2009, P. 3)

Além da importante historicização da forma e do conteúdo do conceito de família, apresentado anteriormente, devemos afirmar também, que, a "família" aqui tratada parte dos moldes ocidentais de relação e que o processo de globalização do capitalismo não pode invisibilizar as questões da diversidade de modelos familiares, apesar, de o capitalismo apontar para a hegemonia nas formas de relação e padronização dos arranjos familiares para seu melhor desenvolvimento, há também a necessidade de destacar que essa generalização acomete as análises de equívocos. "Sem dúvida, o discurso sobre a família está em toda parte. Mas a questão que é frequentemente deixada de lado e que é implícita na crítica de Nzegwu a Appiah é, de que família, família de quem estamos falando? Nitidamente, é a família nuclear Euro-Americana que é privilegiada, às custas de outras formas de família" (OYĖWÚMI, O., 2000, p. 1094)

Sobre esse fato Oyèwúmi ainda discorre:

A família nuclear de muitos estudos feministas produz um cálculo falho de gênero, a categoria que reivindica seu resultado como zero. Ao invés de interpretar a família nuclear branca como uma forma culturalmente específica, cujas características raciais e de classe são essenciais para a compreensão da configuração de gênero que abriga, muitos estudos feministas continuam a reproduzir suas distorções através do espaço e do tempo. (OYÈWÚMI, O., 2000, p. 1094)

Saffioti afirma em seu artigo A questão da mulher na perspectiva socialista (2013, p. 84): "A família enquanto instituição social não pode ser pensada como imutável. Entre a família antiga na sua forma grega ou oriental, e a família cristãogermânica há grandes diferenças, embora haja também um laço de continuidade histórica".

Apresentadas essas questões, retomo a discussão em relação à família nuclear ocidental, a qual, apontamos como fundamentalmente ligada ao desenvolvimento do capitalismo, sendo necessária a sua manutenção para que haja possibilidade de produção sem a responsabilidade do capital e do Estado com a reprodução da vida dos trabalhadores e trabalhadoras. Nesse caso, a 
família é o ente privado que é resguardado pelo trabalho invisibilizado das mulheres, o espaço que somado ao trabalho produtivo, retira do grupo social feminino todo "produto disponível", por meio da sexagem, ou seja, estão inclusos o afeto, o corpo, a sexualidade, o tempo de vida, os direitos sexuais e reprodutivos e a força de trabalho.

[...] Este no debe ser entendido solamente como el espacio cotidiano del hogar y sus tareas, sino como un mandato de género en pos de los demás, asociado además al amor y al cuidado. Este concepto permite entender como, en realidad, la participación de las mujeres en la esfera pública no supone una liberación de los mandatos culturales, porque además el espacio privado de recreación y goce personal, esta también negativizado para las mujeres. (CASTRO, 2009, P. 3)

Assim, no momento em que as mulheres subvertem a ordem e se organizam na luta pelo direito à moradia, ao lar, consiste em uma luta que ultrapassa os limites da estera da reprodução, guardando estreita articulação com as condições mais gerais de produção da existência, sendo, na verdade, domínios inseparáveis, imbricados. Ousar lutar por teto, por alimento, por escola, arruamento, iluminação por água e por postos de saúde revela essa falsa dicotomia entre a "Rua" e o "Lar" e contribui para a formação de consciências críticas e que comprometam mais e mais pessoas - mulheres e homens na grande tarefa de revolucionar não só as condições de produção material da vida, mas, também, as relações sociais de sexo.

\section{(DES) CAMINHOS METODOLÓGICOS: O MOVIMENTO FEMINISTA NA LUTA PELO ESPAÇO URBANO}

As estratégias do movimento feminista no âmbito do reconhecimento dos direitos se deram no sentido de visibilizar que a apropriação do capital no espaço urbano está permeada por ideologias e práticas patriarcais e racistas, tão quanto estão as relações na sociedade. Demandar a garantia de direitos pelo Estado, a partir do reconhecimento deste como lócus de (re)produção dessas práticas, significa desconstruir as premissas que constituem a sua autoridade e poder na função de resguardar os privilégios de alguns grupos.

Enquanto corpo teórico e prática política, o feminismo - ou os feminismos - fala a partir de experiências múltiplas e corpos diversos, que dão lugar a uma pluralidade de demandas e movimentos: os feminismos das mulheres negras, das indígenas, das quilombolas, das ribeirinhas, das socialistas, o transfeminismo, e outras tantas nomeações que nos chamam atenção para a diversidade que marca, e desestabiliza, a categoria mulher. E que também repercute nos modos como essas mulheres experienciam a vida urbana.

Neste sentido, podemos afirmar, que estamos tratando aqui de movimentos feministas urbanos, refletindo coletivamente a partir das experiências de mulheres que estão disputando e construindo o direito à cidade a partir de uma perspectiva feminista, que se colocam no enfrentamento de desafios contemporâneos que estão postos para os movimentos de mulheres que têm o espaço urbano como uma pauta central. 
Para fins de discussão no presente trabalho, tentamos refletir sobre 0 modo como o movimento feminista contribui para as perspectivas metodológicas embasadas pela crítica, pela reflexividade e pela busca da mudança social. $\mathrm{O}$ feminismo tem sido caracterizado pela procura de ferramentas analíticas para analisar e compreender as relações diferenciadas de poder que situam as mulheres em posições desiguais e assim, tentar promover a modificação dessas posições. Isso traz grandes questões para a luta pelo direito à cidade, já que, direito à cidade é visto aqui como algo de completude, que atinge as condições de dignidade na vida e no trabalho, nos direitos sociais, sejam eles vividos no âmbito da moradia, ou no âmbito do território ampliado, do bairro, do local de trabalho, no transporte público.

O feminismo é movimento político, mas, é também, um projeto teóricoepistemológico que traz importantes avanços para o desenvolvimento de pesquisas e das plataformas de lutas, nos mais diversos movimentos sociais, sejam eles mistos ou auto-organizados. As epistemologias e metodologias feministas, assim como o pensamento feminista, não é um campo estável, uma vez que existem várias formas de se produzir conhecimento a partir das diferentes teorias. As epistemologias feministas se caracterizam por ser um campo multidisciplinar, defenderem a pluralidade metodológica e entenderem que homens e mulheres produzem ciência de formas diferentes.

As metodologias feministas têm trazido nos últimos anos novas possibilidades para o estudo das dinâmicas sociais. Um dos principais pontos ressaltados é a responsabilidade do/a pesquisador/a no trabalho científico, ou seja, a necessidade da adoção de uma postura reflexiva tanto durante o processo de pesquisa quanto às implicações dos resultados da sua investigação. As metodologias de caráter feminista têm resgatado o valor da crítica e da reflexão na avaliação dos efeitos da dimensão social e relacional na produção dos discursos científicos, a reflexividade é um instrumento de crítica e pressuposto intransponível dentro das metodologias feministas.

No modo tradicional de fazer ciência positivista, a objetividade foi associada à masculinidade, estando à objetividade científica ligada a uma separação entre razão e emoção, o feminismo dentro da ciência contesta essa noção de objetividade, de verdade e de neutralidade que estava muito presente no conhecimento científico. Para as epistemologias feministas, o conhecimento é sempre posicionado e contrário à imparcialidade, uma vez que é necessário ser parcial, se comprometer com o saber produzido na busca pela mudança social. É com base neste princípio da igualdade entre os sexos que as metodologias feministas pretendem, acima de tudo, garantir a criação de um compromisso científico, social, cultural e político que legitime e valorize, numa perspectiva de equidade, as experiências dos homens e das mulheres, bem como os significados que homens e mulheres constroem acerca das suas realidades sociais.

Nesse sentido, essa forma de produzir ciência vai ter uma relação importante com grupos minoritários, grupos que estão em situação de desigualdade social, em especial às mulheres. A opção da pluralidade metodológica pelos/as investigadores/as feministas é assim uma opção técnica deliberada, na medida em que expressa preocupações em prol do compromisso que esta visão da ciência assume face à mudança social.

Entendemos que as pesquisas de inspiração feminista têm contribuído para a tematização da transformação social, do engajamento político, e das 
desigualdades sociais. Isso nos traz importantes contribuições quando refletimos sobre que possíveis mudanças gostaríamos que a ciência pudesse influenciar no mundo social, e, sobretudo na transformação das formas de se analisar e de se produzir as cidades.

As mulheres do movimento feminista em Salvador se organizam das mais diversas formas, me atenho a falar da Marcha Mundial das Mulheres, movimento de escala internacional, que se organiza enquanto frente, que abarca muitas identidades políticas, porém, todas devem caber nos princípios do anticapitalismo, anti-racismo, anti-patriarcal e anti-Igbtfóbico. É um feminismo que tem por esses princípios o método de auto-organização, como fundamental e estruturante do modelo de organização. A MMM está no campo e na cidade, em muitos países do mundo inteiro, e começou no Canadá, mas, já está nos cinco continentes.

A sua plataforma de lutas envolve o direito ao trabalho, ao aborto, a luta contra a violência, a luta pelos bens comuns, as reivindicações para a responsabilização do Estado e também dos homens pelo trabalho doméstico e de cuidados, a visibilização do trabalho da mulher, a igualdade, a justiça. Todas essas pautas são traduzidas em suas ferramentas de luta, e, que nesse caso, falaremos em como eles se expressam na cidade. O uso das pichações, da batucada feminista, dos lambe-lambes, são formas de ocupar as ruas, são parte do método do movimento para reivindicação do espaço da rua como um espaço da luta feminista.

Portanto, acredito que seja possível analisar os diferentes modos de acesso, uso e apropriação do espaço urbano, de modo a apreender as múltiplas diferenças e desigualdades, a partir da interação entre diferentes eixos da subordinação de mulheres - sexo, raça e classe -, incluindo também o conceito de patriarcado nas suas diferentes formas de expressão. Nesta direção, a imbricação de sexo, raça e classe contribuem para a captura da vulnerabilidade particular de mulheres cuja relação com o espaço urbano está intimamente relacionada com a construção do Direito à Cidade.

A construção do direito a uma vida que vale a pena ser vivida nas cidades passa pelo enfrentamento às desigualdades de classe, raça e gênero, que se aprofundam nas cidades organizadas pela lógica de mercado. Esta lógica segrega a população, concentra a riqueza e prioriza a circulação de mercadorias para a reprodução do capital. Enfrentar essa lógica excludente significa incorporar a experiência das mulheres para que os espaços públicos, a gestão da cidade e a participação política sejam organizados para além da experiência masculina de vida e mobilidade. Dessa forma, a auto-organização das mulheres impõe uma nova sociabilidade, é o local da organização política, o qual, para além de ter a capacidade de elevação de consciência, é também um novo espaço ao qual as mulheres passam a ocupar.

Uma cidade mercantilizada é uma cidade onde quem domina é a especulação imobiliária, os serviços pagos, a cultura e os espaços públicos privatizados, as empreiteiras e os investidores do grande capital. Quando o mercado avança, o Estado e os serviços públicos como creches, saúde e educação são atacados e, mais uma vez, quem paga a conta são as mulheres. A Marcha Mundial das Mulheres, ao levarem para as ruas suas metodologias de luta, como a agitação e propaganda, por exemplo, com a colagem de "lambelambe" pelas ruas, disputa ideologicamente o espaço urbano. Traz às cidades 
um caráter de cidade-denúncia, em que seus muros são destinados à educação política feminista.

Uma outra ferramenta fundamental da MMM é a batucada feminista, que colore as ruas nas manifestações feministas. Esse instrumento não é apenas uma forma de fazer barulho. Para além do intuito de se fazer escutar e dialogar com a sociedade, a batucada se baseia em um processo de construção coletiva, que vai desde a coleta das latas pelas ruas da cidade, à decoração, e o momento de tocar, aprendendo juntas, com ritmos simples, palavras de ordem, e "papo reto". Ao caminhar pelas cidades, as mulheres da marcha entram em contanto com uma infinidade de pessoas, que se veem e se escutam naquele cancioneiro.

O olhar sobre essas metodologias de organização e luta feministas pode nos trazer aspectos importantes para o papel do movimento feminista na transformação social. O território é um princípio do movimento, visto que, a dificuldade de mobilidade das mulheres pelas cidades é uma realidade concreta, e por isso, organizar a luta em seu local de moradia, local de trabalho ou de estudos, é uma estratégia também colocada em prática pela Marcha.

\section{CONSIDERAÇÕES}

A perspectiva feminista aponta a necessidade de se construir um novo paradigma de urbanização que amplie a visão de uso e ocupação do solo, que, muitas vezes, não incorpora as relações humanas como parte dos conflitos e das relações de poder que tem que ser alteradas. A subordinação das cidades à lógica da exploração e do mercado encontra paralelo na subordinação das mulheres. Assim como o espaço geográfico, o tempo e trabalho das mulheres são vistos como recursos inesgotáveis.

Assim, por meio das apropriações advindas das relações de "raça" /etnia e sexo, o capitalismo amplia um grande contingente humano disponível para os mais baixos salários, aumentando, portanto, a sua capacidade de exploração do trabalho associada a essas apropriações. A cidade é o local onde o capitalismo se expressa com maior intensidade, é o local de produção e reprodução da vida dos trabalhadores e trabalhadoras, é então, nesse lócus, que as características do sistema capitalista-patriarcal-racista aparecem de forma mais contundente.

Afirmo, a partir do que foi construído como caminho teórico nesse texto, que o Espaço Geográfico, a partir dos seus vários mecanismos, com diferentes atores, que representam os diferentes interesses, tendem, hegemonicamente à reprodução das relações sociais de sexo, perpetuando as condições de vulnerabilidade e subalternidade às mulheres. Porém, é também nesse espaço, em que as mulheres resistem, constroem relações de solidariedade para sobreviverem e se auto organizam para lutar por direitos.

Se, partimos aqui, da perspectiva de que as categorias sexo, raça/etnia e classe são estruturantes da nossa sociedade, devemos reforçar que essa imbricação é fundamental para a sustentação desses sistemas, que operam em todas as relações sociais, conferindo à estas, condições diferenciadas, de acordo com o que as determina. Uma mulher, negra, periférica, vive hoje as contradições dessa sociedade, tendo o seu corpo e sua vida controlada por esse sistema, o que a faz viver a cidade sem direitos, sem acesso, de forma diferente de um homem negro, uma mulher branca, ou um homem branco.

O direito à cidade, que significa uma transformação profunda na organização das cidades, que alterem as relações sociais, que rompam de fato 
com o capitalismo, o patriarcado e o racismo, é uma pauta fundamental para a vida das mulheres trabalhadoras, e essa demanda se expressa fortemente nos movimentos de luta por moradia, por exemplo, onde as mulheres são as principais sujeitas, e que reconhecem nesse espaço, a luta pelo poder, pelo caminhar e viver a cidade de forma plena.

Com a inclusão do direito à cidade na Nova Agenda Urbana, há de se considerar uma premissa no que tange às mulheres e a cidade: as mulheres são muitas e diversas entre si. Compartilham de diferentes experiências de acesso de acordo com raça, classe, sexualidade e identidade de gênero; categorias que posicionam determinados locais sociais para cada uma das sujeitas. Desta maneira, o próprio conceito de direito à cidade se flexibiliza, para que assim, possa ser pensado para todas, as diversas mulheres.

As questões trazidas nesse artigo não visam fechar ciclos, ou responder todas as questões, é, enfim, um exercício de teorização a partir de duas áreas da ciência, nas quais estou inserida. A geografia feminista é um caminho, para ocupar uma ciência altamente masculinizada e que negligencia por muitas vezes os fatores aqui debatidos, mas, que tem em seu seio, pesquisadores/as que resistem e lutam por sua transformação, visando também, a transformação da sociedade.

\section{REFERÊNCIAS}

BONDI L. \& ROSE, D. Constructing gender, constructing the urban: a review of Anglo-American feminist urban geography. Gender, Place and Culture, Nova York, 1992.

CAMACHO, R. S. A produção do espaço e do território: as relações de trabalho subordinadas ao modo de produção capitalista. Entre-Lugar, ano 1, n. 1, 1丷, Dourados, 2010.

CASTRO, M. Marxismo, feminismos e feminismo marxista: mais que um gênero em tempos neoliberais. Crítica Marxista, n. 11, Campinas, 2000.

CORREAA, R. L. O espaço urbano. São Paulo: Ática, 1986.

DAVIS, A. Mulheres, raça e classe. Tradução Heci Regina Candiani. - 1. ed. São Paulo: Boitempo, 2016.

HARAWAY, D. J. (1991). Simians, cyborgs, and women: the reinvention of nature. London: Free Association Books.

HUXLEY, M. E EINCHESTER, H. P. M. Residencial differentiation and social reproduction: the interrelations of class, gender, and space. In: Environment and Planning D: Society and Space, v. 9, n 2, Great Britain: Pion Limited, 1991.

McDOWELL, L. (1983) Towards an understanding of the gender division of urban space. Environment and Planning D: Society and Space, 1(1), 15-30.

(1999). Gender, identity and place: understanding feminist geographies. Minneapolis: University of Minnesota Press.

MARTíNEZ, Ana S., MOYA, Juana R. e MUNOZ, M. Mujeres, Espacto y 
Sociedad - Hacia una Geografía del Género. Madrid: Síntesis, 1995.

MARX, K. Para a Crítica da Economia Política. São Paulo: Abril Cultural 1984 [1859].

MOREIRA, R. Pensar e ser em geografia: ensaios de história, epistemologia e ontologia do espaço geográfico. Contexto, São Paulo, 2004.

. O Que é Geografia. Brasiliense, São Paulo,1985.

OYĖWÚMI, O. Family bonds/Conceptual Binds: African notes on Feminist Epistemologies. Signs, Vol. 25, No. 4, Feminisms at a Millennium. Tradução para uso didático por Aline Matos da Rocha. 2000.

RAINEIRO, L. Indicadores Urbanos de Género Instrumentos para la gobernabilidad urbana. CISCSA: Córdoba, Argentina, 1988.

ROSSINI R. E. A produção do novo espaço rural: pressupostos gerais para a compreensão dos conflitos sociais no campo. CAMPO-TERRITÓRIO: revista de geografia agrária, v. 4, n. 8, p. 5-28, 2009.

SAFFIOTI, H. A mulher na sociedade de classes. Mito e Realidade. São Paulo: Expressão Popular, 2013.

SILVA, J. M. Não Excluam Metade da Humanidade da Geografia Humana: entrevista com Janice Monk. Revista Latino-americana de Geografia e Gênero, Ponta Grossa, v.1, n.1, p. 148 - 152, jan. / jul. 2010 